\title{
Clinical Effects of Novel Nanoscaled Core Decompression Rods Combined with Umbilical Cord Mesenchymal Stem Cells on the Treatment of Early Osteonecrosis of the Femoral Head
}

\author{
Hongyang Gao, ${ }^{1}$ Guoping Zhang,' Jian Wang, ${ }^{1}$ Feng Zhao, ${ }^{1}$ Yuchen Zhang, \\ Wei Wang, ${ }^{1}$ and Yang You ${ }^{2}$ \\ ${ }^{1}$ Department of Orthopedics, The First Hospital of Hebei Medical University, Shijiazhuang 050031, China \\ ${ }^{2}$ Department of Cardiovasology III, The First Hospital of Hebei Medical University, Shijiazhuang 050031, China
}

Correspondence should be addressed to Yang You; ghy0618@yahoo.com.cn

Received 11 December 2014; Accepted 29 January 2015

Academic Editor: Shuming Zhang

Copyright (c) 2015 Hongyang Gao et al. This is an open access article distributed under the Creative Commons Attribution License, which permits unrestricted use, distribution, and reproduction in any medium, provided the original work is properly cited.

Osteonecrosis of the femoral head (ONFH) is one of the most common diseases in orthopedics. In this study, we investigated the clinical effects of novel nanoscaled core decompression rods combined with mesenchymal stem cells on the treatment of the ONFH. 12 adult patients with early ONFH (at the stage of Ficat II) received the treatment using the implantation of novel nanoscaled core decompression rods combined with umbilical cord mesenchymal stem cells. The grade of the patients' hip was scored by Harris marking system before and after the surgery, and then paired $t$-test was done. We assessed the curative efficiency based on the change of the patients before and after the surgery. In particular, the survival rate of femoral head was assessed at 12 months after the surgery. The results demonstrated that according to the standard of Harris Scoring, the average grade of hip joint before the surgery was $54.16 \pm 4.23$ points while average grade of hip joint at 12 months after the surgery was $85.28 \pm 3.65$ points. So, the implantation of the novel nanoscaled core decompression rods combined with mesenchymal stem cells had satisfactory clinical effects, suggesting that this implantation should be effective to treat early ONFH.

\section{Introduction}

Osteonecrosis of the femoral head (ONFH), which is caused by the interruption of blood supply [1], is one of the most common diseases in orthopedics [2], with an average age of occurrence accounts to be 38 years old, and highest incidence rates for young people. At present, total hip replacement is commonly used in the treatment of patients suffering from ONFH [3]. However, it has been reported that prosthetic replacement in young patients with ONFH has a poor durability [4]. Generally speaking, core decompression (CD), electrical stimulation, and vascularized bone grafting are the three most commonly used method for the treatment of early stage ONFH $[5,6]$. According to the previous report, surgical core decompression has an excellent treatment effect on the osteonecrosis of hip and knee [7-13]. Core decompression
(CD) is employed in wide treatment of hip osteonecrosis in its early stages (before mechanical failure has occurred) $[10,14-17]$. Owing to the incomplete reconstruction necrotic area by core decompression, the effect of core decompression is not always satisfactory [18]. Moreover, the deficiency of osteoprogenitor cells of the osteonecrotic hip also restricts its implication [19-21]. Owing to the incomplete reconstruction necrotic area by core decompression, its efficacy still remains to be controversial [10]. It has been reported that if the ONFH cannot be treated effectively and actively, the majority of patients' femoral head will collapse in $2-3$ years [22, 23]. Ideal therapeutic procedure should include (1) cleaning the bone lesions as far as possible and (2) implant possessing adequate biological activity and mechanical supporting to avoid early collapse of the femoral head. Recently, bone marrow mesenchymal stem cells (BMSCs) have attracted great attention 
[24-28]. Due to their ability to differentiate into multiple cell lineages including osteoprogenitor cells, a successful use of BMSC after making a single drill hole into the avascular area in patients who has atraumatic osteonecrosis has been reported [25-32].

In this work, we used the implantation of a novel nanoscaled core decompression rod combined with umbilical cord mesenchymal stem cells to cure 12 cases of early ONFH, with complete follow-up for all of them. Their period of follow-up was more than 12 months. The aim of the present study is to investigate the clinical effects of implantation with the novel nanoscaled core decompression rod combined with umbilical cord mesenchymal stem cells on the treatment of early ONFH.

\section{Experimental Materials and Methods}

2.1. Materials. The supporting material used in this study was porous nanoscaled core decompression bar from Guona Technology Co. Ltd in Sichuan. The cell therapy center in the first hospital of Hebei Medical University provided the stem cells required for the treatment. Under the situation of acquiring the consent of delivery woman and approval of the ethics committee, we got the umbilical cord mesenchymal stem cells from healthy pregnant women after caesarean in the Department of Obstetrics and Gynecology, the First Affiliated Hospital of Hebei Medical University.

2.2. Surgical Method. The patient lies on the hospital bed, and we anaesthetized patients using the injection of spinal canal. The channel of core decompression was determined under the guide of C-armed fluoroscopy. A $5 \mathrm{~cm}$ incision was obtained in the lateral femoral, making the lateral cortical bone exposed. Meanwhile, the hip at internal rotation of $15^{\circ}$ was kept and the guide pin in the perspective along the direction of femoral neck was inserted. The far-end of guide needle reached the center of osteonecrosis of the femoral head, the length of nail was measured using depth gauge, and the dead tissue was removed by using rotary cutter after the reaming of hollow drill (with a diameter of $12 \mathrm{~mm}$ ), and the taping treatment of the near-end of the pressure relief channel was conducted using tap. Fresh autogenous cancellous bone was collected from intertrochanteric region in the course of decompression process, mixed fresh autogenous cancellous bone, and prepared allogeneic mesenchymal stem cell suspension $(5 \mathrm{~mL})$ fully for later use. Nanoscaled core decompression rod was screwed in using a controller, and the tail of decompression rod was embedded in bone cortex slightly. Then, the rest of $5 \mathrm{~mL}$ cell suspension was injected into the hollow channel of the decompression rod. Finally, the hollow channel was sealed using gelatin sponge and bone wax in order to minimize the loss of the cells.

2.3. Treatment after the Surgery. The exercises of the patients after anesthesia recovery were guided by researchers. We encouraged patients to expand hip joint and make active flexion and extension and functional exercises. Moreover, there was no restriction on the movement of patients' hip joint under the condition of nonweight bearing. Patients' hip joint was forbidden to load in 2 months after surgery. Some loading could be imposed on the patients' hip joint 3 months after surgery.

2.4. Observation and the Evaluation Standard. The observation was carried out 1, 2, 3, 6, and 12 months after the surgery, respectively. In order to check whether the supporting material had the sigh of loosing or not and the improvement of radiological staging of the $\mathrm{ONFH}$, the picture of front and frog leg position of pelvis was taken. The change of pain and the range of movement of patients' hip were recorded before and after the surgery and the grade of patients' hip was scored using Harris marking system. The evaluation standard of the treatment was collapse of the femoral head or final hip replacement.

2.5. Statistical Analysis. Paired $t$-test was conducted on the Harris score of patients' hip before and after the surgery using statistical software SPSS17.0. $P<0.05$ indicated that there was a statistical difference.

\section{Results}

According to the standard of Harris Scoring, the average grade of hip joint before surgery was $54.16 \pm 4.23$ points while average grade of hip joint 12 months' follow-up after surgery was $85.28 \pm 3.65$ points. So the Harris Scoring raised distinctly $(P<0.05)$. On the basis of Harris Scoring, points from 91 to 100 was excellent level, points from 81 to 90 was relatively excellent level, points from 71 to 80 was good level, less than 70 points was bad level, and the excellent and good rate of points in this group was up to $92.2 \%$.

According to the international osteonecrosis staging criteria of World Bone Circulation Research Association, we made a radiological evaluation on our results. With the obvious collapse of osteonecrosis of the femoral head or final joint replacement as the end point of study, the abscission had never occurred to all the 12 samples in this group over 12 months after surgery. Obvious collapse did not happen to any 12 cases; the survival rate of the femoral head was up to $100 \%$ in terms of 12 samples (patients' hip) 12 months after surgery. Of all the 8 patients whose follow-up periods exceed 12 months, the progress of the disease was discovered in only one case in 18 months after surgery, showing the phenomenon of collapse of femoral head, and dynamic observation was temporarily stopped without any other special treatment.

A typical case of patients' hip was analyzed. The patient was male (31 years old). The patients' left hip suffered from pain without any induction factor and his activity was restricted for 1 year. The patient came to see the doctor after his condition worsened for 3 months. The X-ray and CT pictures of patients' hip indicated that it indeed occurred to the left femoral head osteonecrosis (at the stage of Ficat II) (Figures 1 and 2). Moreover, no obvious osteonecrosis and collapse of femoral head happened after continuous followup of 12 months (Figure 3). 


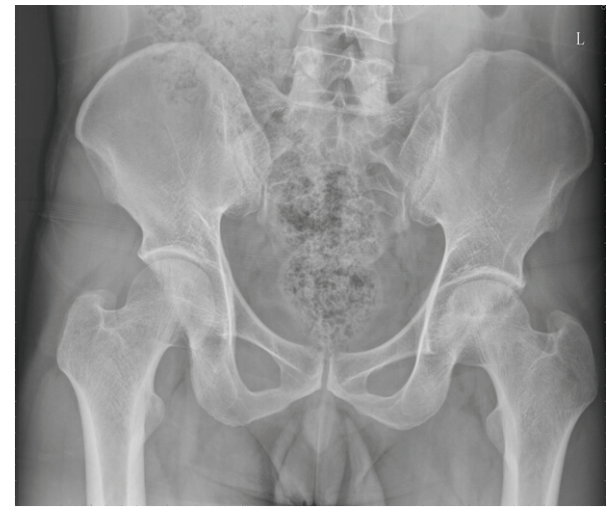

FIGURE 1: X-ray picture of normal position of pelvis (before surgery).

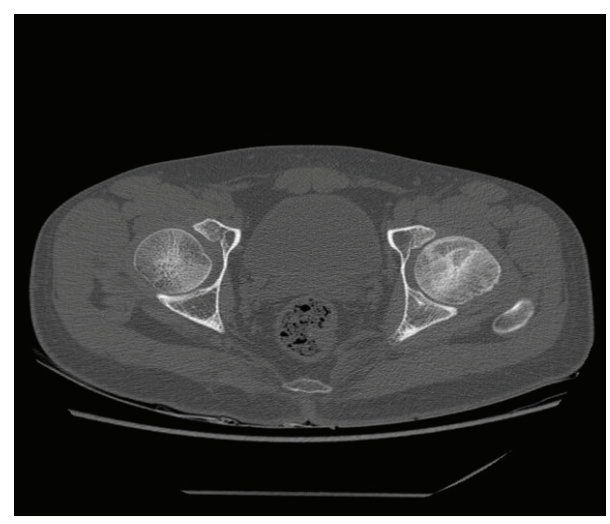

FIGURE 2: CT picture of normal position of pelvis (before surgery).

\section{Discussion}

4.1. The Application of Umbilical Cord Mesenchymal Stem Cells in the Treatment of ONFH. The technology of core decompression for femoral marrow could reduce the internal pressure in the femoral head, thus removing the sclerotic band, creating the new collateral circulations, relieving the pain of the hip joint, and, moreover, completing the repair of femoral head in the end. As with early osteonecrosis of the femoral head, core decompression has been widely recognized as a highly effective manner in surgical intervention. However, throughout all the earlier achievements, some clinical efficacy has been identified in the joint-preserving cure of early osteonecrosis of the femoral head after decades of constant efforts. The of joint-preserving treatment still has obvious limitations, such as poor treatment effect and low efficiency (only $60 \%-80 \%$ in case of short and midterm treatment) for the majority of patients [33]. Through the analysis of the causes, the potential interpretation was that a simple core decompression may not thoroughly solve the problem of rising of bone marrow pressure [34]. It has been proved that stem cells owned multiple differentiation potential and could differentiate into other cells in certain direction under the action of specific cytokines, thus making a difference in the repair of damaged tissue. The application of stem cells provided an entirely new thought to the joint-preserving treatment of early osteonecrosis of the femoral head. At present, transplantation of bone marrow mesenchymal stem cells which combined femoral marrow core decompression has been widely used in joint-preserving treatment of osteonecrosis of the femoral head [35]. Umbilical cord mesenchymal stem cells had the same biological characteristics as bone marrow mesenchymal stem cells and possessed the capability of totipotent differentiation potential in all directions; almost all tissue cells of human body could be differentiated from umbilical cord mesenchymal stem cells. It has been demonstrated that umbilical cord mesenchymal stem cells have excellent osteogenic ability, which is very useful to repair the large segmental bone defect [36]. What is more, umbilical cord mesenchymal stem cells could improve the local blood supply of osteonecrosis of the femoral head and initial effect in the treatment of early osteonecrosis of the femoral head [37]. In this study, umbilical cord mesenchymal stem cells were used as the seed cells in the reconstruction of the femoral head. On one hand, the strong differentiation and proliferation ability of umbilical cord mesenchymal stem cells could improve the bone microcirculation, promote the regeneration of vascular endothelial cells, and ameliorate venous reflux in lesions. On the other hand, intraosseous pressure will be decreased, and the blood supply of the femoral head will be restored and improved, creating favorable environment for newly born bone. In contrast to mesenchymal stem cells derived from bone marrow, the application of umbilical cord mesenchymal stem cells did not involve argument in ethical, social, legal, and other aspects; moreover, the source of umbilical cord mesenchymal stem cells is sufficient, the separation of cells is simple, and the cell viability of cells is powerful. Finally, in addition to lower probability of infectious diseases, umbilical cord mesenchymal stem cells are easier to amplification in vitro; all advantages mentioned above make them perfect for the clinical applications as seed cells.

4.2. The Selection of Supports after Core Decompression of ONFH. Experts and scholars from home and abroad hold the common view that an implant was needed for providing the mechanical support in the area of bone defect to avoid or delay the collapse of femoral head. Moreover, an ideal support should meet at least two key criteria: (1) biological factors, namely, good bone-induced and bone conduction activity are necessary for supports, and bone defect caused by the removal of the necrotic bone residue could be repaired by the implantation of the implant; moreover, the implant should offer the necessary mechanical support for bone formation; (2) biomechanical factors, the implant should provide some mechanical support for femoral head to avoid or delay the collapse of the articular surface of the femoral head [38]. On the basis of these two points, supports commonly used are impaction bone grafting with simple bone tunnel, vasal bone transplantation, implantation of tantalum rod, and so on. The pure impaction bone grafting has been proved to be failed to provide sufficient mechanical support for the cartilage of femoral head. Although vascularized bone grafts could improve local blood supply and promote 


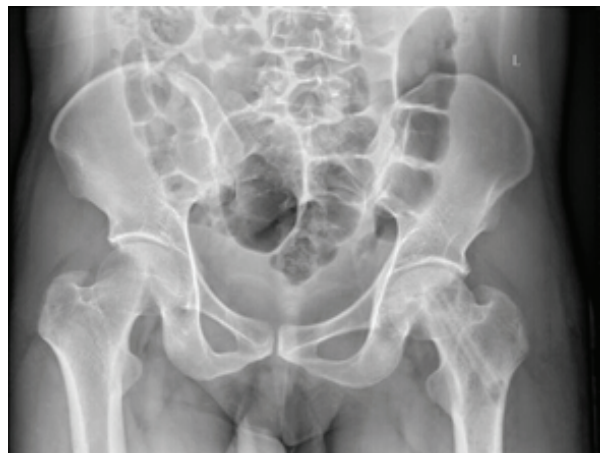

1 month after operation

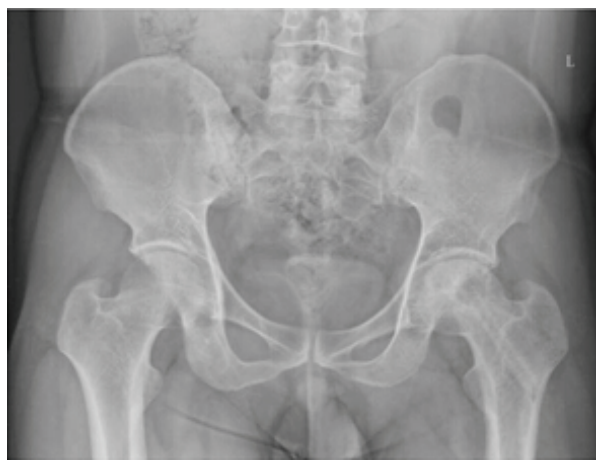

6 months after operation

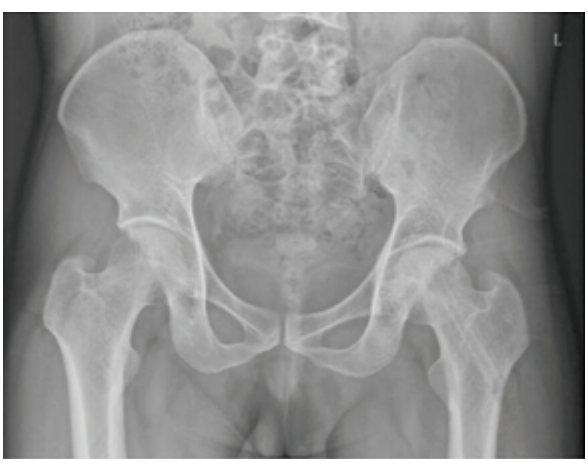

3 months after operation

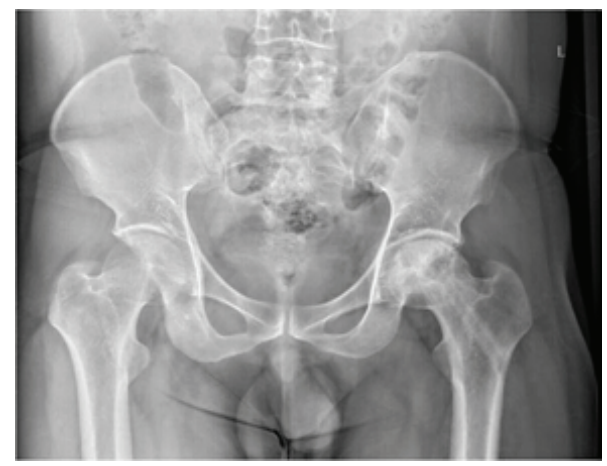

12 months after operation

FIGURE 3: X-ray picture of normal position of pelvis at the 1th, 3rd, 6th, and 12th month after surgery.

the formation of new bone, the length of vascular pedicle restricted the movement of hip joint undoubtedly, giving rise to inevitable influence on the recovery of patients' hip after surgery. More importantly, vascularized bone grafts had higher requirements on the microsurgical technique and other disadvantages, such as the difficulty of surgery in the operation and relatively large trauma, limiting their clinical application.

In this study, we selected porous nanocore decompression rod as supporting material, with core decompression rod designed by Guona Technology Co. Ltd, Sichuan. The main components of supporting material are nanohydroxyapatite/polyamide 66 (nano-HA/PA66). Due to the good compatibility and biological activity of nano-HA/PA66, it has gained an excellent effect as a new type of bone substitute material [39-42]. In comparison with other supporting materials, the molecular and structural characteristics of nanoHA/PA66 not only ensured its good mechanical supporting capability, but also provided incomparable biological activity and bone conduction, which is the biggest advantage of novel nanocore decompression rod $[43,44]$. Additionally, the unique design of hollow and porous nanocore decompression rod allows autogenous bone particles to fill in the hollow cavity, favoring the fusion of implant and the bone. Multiporosity of perisporium could also increase the environmental channel for bone graft, creating excellent microenvironment for the growth of new bone. Mesenchymal Stem Cells in the Treatment of ONFH. Seed cells and bone scaffold materials are the two major elements of bone tissue engineering. In recent years, some researchers have attempted to form tantalum bars composites containing mesenchymal stem cells to promote the neovascularization of materials [45]. Compared with tantalum metal phase, nanoHA/PA66, as a nonmetal biomimetic material, possesses pore structure mimicking the structure and morphology of natural cancellous bone. The dual culture of external mesenchymal stem cells and nano-HA/PA66 showed that the cell proliferation and cell biological characteristics of mesenchymal stem cells cultured on the nano-HA/PA66 materials are similar to that of mesenchymal stem cells cultured alone, indicating that nano-HA/PA66 materials are beneficial to the growth, bone adhesion, and differentiation of mesenchymal stem cells [46]. More importantly, by means of promoting the formation of new vessels, accelerating the bone transformation, preventing chondrocytes' apoptosis, and finally serving the purpose of promoting the bone repair, the addition of mesenchymal stem cells into nano-HA/PA66 composites has an extremely important significance in treating early revascularization [47-50].

\section{Conclusions}

In our study, on the basis of core decompression, we organically combined two main elements in bone tissue engineering, cells (umbilical cord mesenchymal stem cells) and scaffolds (nanoscaled core decompression rods), to treat the early osteonecrosis of the femoral head. According to the standard of Harris Scoring, the average grade of hip joint 
before surgery was $54.16 \pm 4.23$ points while average grade of hip joint 12 months' follow-up after surgery was $85.28 \pm 3.65$ points. The clinical effect was significant, suggesting that this implantation is effective to treat early osteonecrosis of the femoral head.

\section{Conflict of Interests}

The authors have no conflict of interests.

\section{Authors' Contribution}

Hongyang Gao and Guoping Zhang contributed equally to this work.

\section{References}

[1] Y. Assouline-Dayan, C. Chang, A. Greenspan, Y. Shoenfeld, and M. E. Gershwin, "Pathogenesis and natural history of osteonecrosis," Seminars in Arthritis and Rheumatism, vol. 32, no. 2, pp. 94-124, 2002.

[2] M. A. Mont, L. C. Jones, S. David et al., "Nontraumatic osteonecrosis of the femoral head: ten years later," The Journal of Bone and Joint Surgery. American Volume, vol. 88, pp. 1117-1132, 2006.

[3] K. L. Lee, G. A. Ngai, S. C. Varghese, L. Duan, and J. A. Cooper, "Nanostructures for ligament and tendon regeneration," Journal of Biomaterials and Tissue Engineering, vol. 3, no. 4, pp. 409-425, 2013.

[4] X. M. Li, Y. Yang, Y. B. Fan, Q. L. Feng, F.-Z. Cui, and F. Watari, "Biocomposites reinforced by fibers or tubes as scaffolds for tissue engineering or regenerative medicine," Journal of Biomedical Materials Research Part A, vol. 102, no. 5, pp. 15801594, 2014.

[5] F. A. Petrigliano and J. R. Lieberman, "Osteonecrosis of the hip: novel approaches to evaluation and treatment," Clinical Orthopaedics and Related Research, no. 465, pp. 53-62, 2007.

[6] M. A. Mont, L. C. Jones, and D. S. Hungerford, "Nontraumatic osteonecrosis of the femoral head: ten years later," The Journal of Bone \& Joint Surgery-American Volume, vol. 88, no. 5, pp. 1117-1132, 2006.

[7] F. P. Castro Jr. and R. L. Barrack, "Core decompression and conservative treatment for avascular necrosis of the femoral head: a meta-analysis," American Journal of Orthopedics, vol. 29, no. 3, pp. 187-194, 2000.

[8] C. G. Zalavras and J. R. Lieberman, "Osteonecrosis of the femoral head: evaluation and treatment," Journal of the American Academy of Orthopaedic Surgeons, vol. 22, no. 7, pp. 455464, 2014.

[9] M. A. Mont, P. S. Ragland, and G. Etienne, "Core decompression of the femoral head for osteonecrosis using percutaneous multiple small-diameter drilling," Clinical Orthopaedics and Related Research, no. 429, pp. 131-138, 2004.

[10] J. R. Lieberman, "Core decompression for osteonecrosis of the hip," Clinical Orthopaedics and Related Research, no. 418, pp. 2933, 2004.

[11] F. Specchiulli, "Core decompression in the treatment of necrosis of the femoral head. Long-term results," La Chirurgia Degli Organi di Moviment, vol. 85, no. 4, pp. 395-402, 2000.

[12] S. Patel, "Primary bone marrow oedema syndromes," Rheumatology, vol. 53, no. 5, Article ID ket324, pp. 785-792, 2014.
[13] M. A. Mont, L. C. Schon, M. W. Hungerford, and D. S. Hungerford, "Avascular necrosis of the talus treated by core decompression," The Journal of Bone and Joint Surgery Series B, vol. 78, no. 5, pp. 827-830, 1996.

[14] A. J. Marti-Carvajal, I. Sola, and L. H. Agreda-Perez, "Treatment for avascular necrosis of bone in people with sickle cell disease," Cochrane Database of Systematic Reviews, vol. 7, Article ID CD004344, 2014.

[15] N. F. SooHoo, S. Vyas, J. Manunga, H. Sharifi, G. Kominski, and J. R. Lieberman, "Cost-effectiveness analysis of core decompression," The Journal of Arthroplasty, vol. 21, no. 5, pp. 670-681, 2006.

[16] X. Li, Y. Huang, L. Zheng et al., "Effect of substrate stiffness on the functions of rat bone marrow and adipose tissue derived mesenchymal stem cells in vitro," Journal of Biomedical Materials Research Part A, vol. 102, no. 4, pp. 1092-1101, 2014.

[17] D. S. Hungerford, "Treatment of osteonecrosis of the femoral head. Everything's new," The Journal of Arthroplasty, vol. 22, no. 4, pp. 91-94, 2007.

[18] X. Liu, X. Li, Y. Fan et al., "Repairing goat tibia segmental bone defect using scaffold cultured with mesenchymal stem cells," Journal of Biomedical Materials Research Part B: Applied Biomaterials, vol. 94, no. 1, pp. 44-52, 2010.

[19] P. Hernigou, A. Poignard, O. Manicom, G. Mathieu, and H. Rourd, "The use of percutaneous autologous bone marrow transplantation in nonunion and avascular necrosis of bone," The Journal of Bone and Joint Surgery Series B, vol. 87, no. 7, pp. 896-902, 2005.

[20] P. Hernigou, F. Beaujean, and J. C. Lambotte, "Decrease in the mesenchymal stem-cell pool in the proximal femur in corticosteroid-induced osteonecrosis," The Journal of Bone and Joint Surgery Series B, vol. 81, no. 2, pp. 349-355, 1999.

[21] C. Nelson, A. Magge, T. S. Bernard, Y. Khan, and C. T. Laurencin, "Nanostructured composites for bone repair," Journal of Biomaterials and Tissue Engineering, vol. 3, no. 4, pp. 426-439, 2013.

[22] C. C. Chen, C. L. Lin, W. C. Chen, H. N. Shih, S. W. Ueng, and M. S. Lee, "Vascularized iliac bone-grafting for osteonecrosis with segmental collapse of the femoral head," Journal of Bone and Joint Surgery, vol. 91, no. 10, pp. 2390-2394, 2009.

[23] A. I. Stavrakis, N. F. SooHoo, and J. R. Lieberman, "A comparison of the incidence of complications following total hip arthroplasty in patients with or without osteonecrosis," The Journal of Arthroplasty, vol. 30, no. 1, pp. 114-117, 2015.

[24] X. Li, H. Liu, X. Niu et al., "The use of carbon nanotubes to induce osteogenic differentiation of human adipose-derived MSCs in vitro and ectopic bone formation in vivo," Biomaterials, vol. 33, no. 19, pp. 4818-4827, 2012.

[25] G. C. Daltro, V. A. Fortuna, M. A. S. de Araújo, P. I. F. Lessa, U. D. A. B. Sobrinho, and R. Borojevic, "Femoral head necrosis treatment with autologous stem cells in sickle cell disease," Acta Ortopedica Brasileira, vol. 16, no. 1, pp. 23-27, 2008.

[26] X. Li, H. Liu, X. Niu et al., "Osteogenic differentiation of human adipose-derived stem cells induced by osteoinductive calcium phosphate ceramics," Journal of Biomedical Materials Research Part B: Applied Biomaterials, vol. 97, no. 1, pp. 10-19, 2011.

[27] P. Hernigou, "Autologous bone marrow grafting of avascular osteonecrosis before collapse," Revue du Rhumatisme, vol. 62, pp. 650-651, 1995.

[28] P. Hernigou, "Growth factors released from bone marrow are promising tools in orthopedic surgery," Revue du Rhumatisme, vol. 65, no. 2, pp. 79-84, 1998. 
[29] P. Hernigou and F. Beaujean, "Treatment of osteonecrosis with autologous bone marrow grafting," Clinical Orthopaedics and Related Research, no. 405, pp. 14-23, 2002.

[30] Z. Q. Yan, Y. S. Chen, W. J. Li et al., “Treatment of osteonecrosis of the femoral head by percutaneous decompression and autologous bone marrow mononuclear cell infusion," Chinese Journal of Traumatology, vol. 9, no. 1, pp. 3-7, 2006.

[31] V. Gangji, J.-P. Hauzeur, C. Matos, V. de Maertelaer, M. Toungouz, and M. Lambermont, "Treatment of osteonecrosis of the femoral head with implantation of autologous bone-marrow cells: a pilot study," The Journal of Bone and Joint Surgery Series A, vol. 86, no. 6, pp. 1153-1160, 2004.

[32] A. M. Cortizo, G. Ruderman, G. Correa, I. G. Mogilner, and E. J. Tolosa, "Effect of surface topography of collagen scaffolds on cytotoxicity and osteoblast differentiation," Journal of Biomaterials and Tissue Engineering, vol. 2, no. 2, pp. 125-132, 2012.

[33] M. A. Mont, L. C. Jones, and D. S. Hungerford, "Nontraumatic osteonecrosis of the femoral head: ten years later," The Journal of Bone and Joint Surgery-American Volume, vol. 88, pp. 11171132, 2006.

[34] X. Li, H. Gao, M. Uo et al., "Effect of carbon nanotubes on cellular functions in vitro," Journal of Biomedical Materials Research Part A, vol. 91, no. 1, pp. 132-139, 2009.

[35] Z. Li, W. Liao, Q. Zhao et al., "Angiogenesis and bone regeneration by allogeneic mesenchymal stem cell intravenous transplantation in rabbit model of avascular necrotic femoral head," Journal of Surgical Research, vol. 183, no. 1, pp. 193-203, 2013.

[36] M. Cuervas-Mons, J. Narbona, R. Laguna, and J. Vaquero, "Autologous concentrated bone marrow graft in the treatment of femoral head avascular necrosis: clinical outcome after two years of follow up in a non-controlled prospective study," Revista Española de Cirugía Ortopédica y Traumatología, vol. 57, no. 2, pp. 106-110, 2013.

[37] G. E. Garrigues, J. M. Aldridge III, J. K. Friend, and J. R. Urbaniak, "Free vascularized fibular grafting for treatment of osteonecrosis of the femoral head secondary to hip dislocation," Microsurgery, vol. 29, no. 5, pp. 342-345, 2009.

[38] J. K. Koper and J. Jakubowicz, "Correlation of wettability with surface structure and morphology of the anodically oxidized titanium implants," Journal of Biomaterials and Tissue Engineering, vol. 4, no. 6, pp. 459-464, 2014.

[39] A. Palmquist, H. Engqvist, J. Lausmaa, and P. Thomsen, "Commercially available dental implants: review of their surface characteristics," Journal of Biomaterials and Tissue Engineering, vol. 2, no. 2, pp. 112-124, 2012.

[40] L. I. Castelan-Velazco, J. Mendez-Nonell, S. Sanchez-Valdes, and L. F. Ramos-Devalle, "Morphology and osteogenetic characteristics of polyamide/nanohydroxyapatite biocomposites," Polymer Bulletin, vol. 62, no. 1, pp. 99-110, 2009.

[41] H. Wang, Y. Li, Y. Zuo, J. Li, S. Ma, and L. Cheng, "Biocompatibility and osteogenesis of biomimetic nanohydroxyapatite/polyamide composite scaffolds for bone tissue engineering," Biomaterials, vol. 28, no. 22, pp. 3338-3348, 2007.

[42] F. Sun, H. Zhou, and J. Lee, "Various preparation methods of highly porous hydroxyapatite/polymer nanoscale biocomposites for bone regeneration," Acta Biomaterialia, vol. 7, no. 11, pp. 3813-3828, 2011.

[43] S. Zhou, Y.-B. Li, Y.-Y. Wang et al., "The porous structure and mechanical properties of injection molded HA/PA66 scaffolds,"
International Polymer Processing, vol. 29, no. 4, pp. 454-460, 2014.

[44] Y. Xiong, C. Ren, B. Zhang et al., "Analyzing the behavior of a porous nano-hydroxyapatite/polyamide 66 (n-HA/PA66) composite for healing of bone defects," International Journal of Nanomedicine, vol. 9, no. 1, pp. 485-494, 2014.

[45] M. Xu and D. Peng, "Mesenchymal stem cells cultured on tantalum used in early-stage avascular necrosis of the femoral head," Medical Hypotheses, vol. 76, no. 2, pp. 199-200, 2011.

[46] Q. Mengchun, D. Jiupeng, D. Wei et al., "The biological activity of co-culture of bone marrow mesenchymal stem cells and nHA/PA66 scaffold materials," Journal of Oral Science Research, vol. 26, pp. 805-808, 2010.

[47] X. Li, L. Wang, Y. Fan, Q. Feng, F.-Z. Cui, and F. Watari, "Nanostructured scaffolds for bone tissue engineering," Journal of Biomedical Materials Research Part A, vol. 101, no. 8, pp. 24242435, 2013.

[48] M. G. M. G. Penido and U. S. Alon, "Phosphate homeostasis and its role in bone health," Pediatric Nephrology, vol. 27, no. 11, pp. 2039-2048, 2012.

[49] U. Saran, S. G. Piperni, and S. Chatterjee, "Role of angiogenesis in bone repair," Archives of Biochemistry and Biophysics, vol. 561, pp. 109-117, 2014.

[50] S. M. Walzer, E. Cetin, R. Grübl-Barabas et al., "Vascularization of primary and secondary ossification centres in the human growth plate," BMC Developmental Biology, vol. 14, article 36, 2014. 

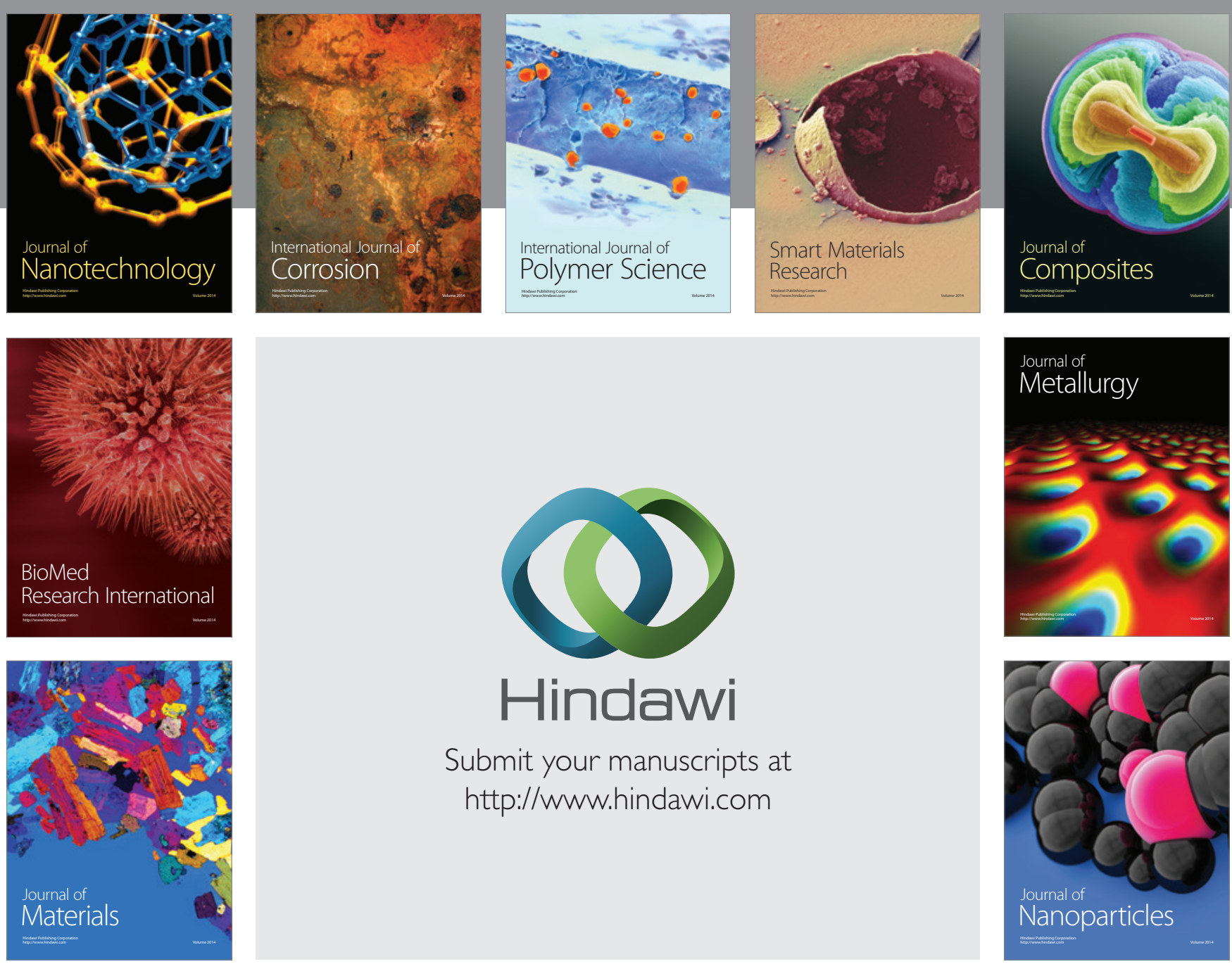

Submit your manuscripts at http://www.hindawi.com
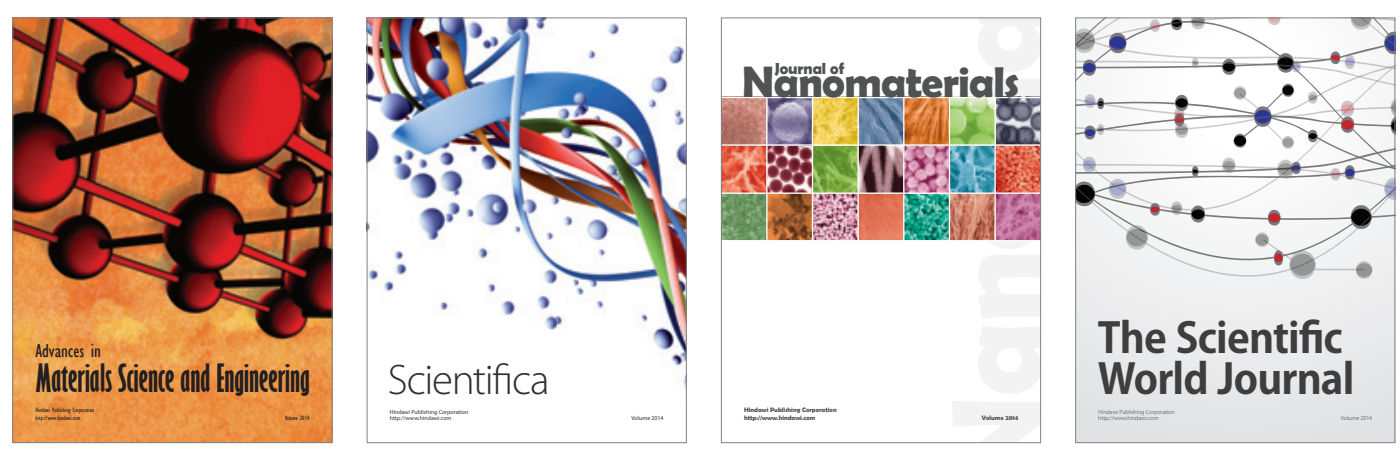

\section{The Scientific World Journal}
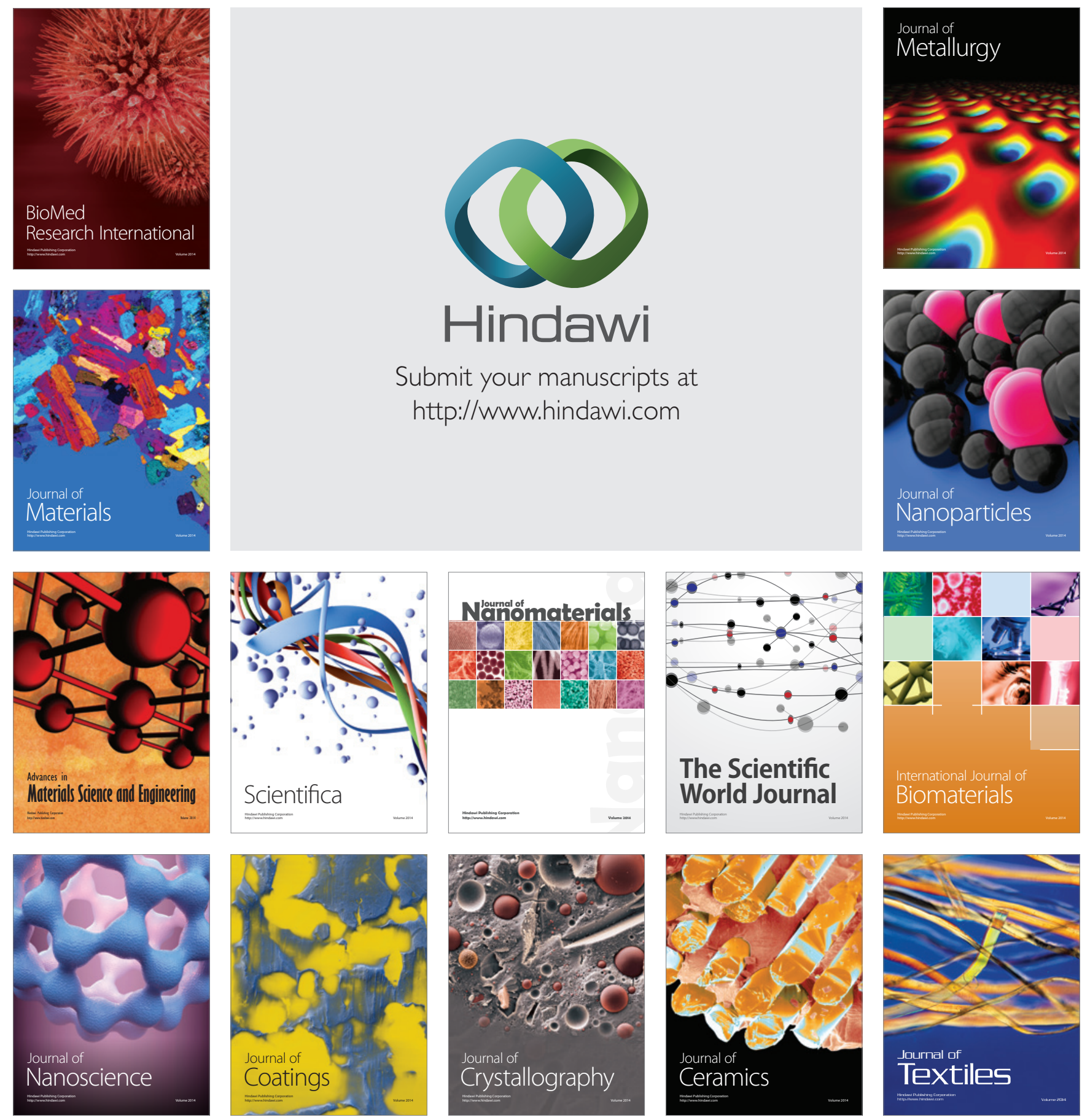